INDEPENDENT JOURNAL OF MANAGEMENT \& PRODUCTION (IJM\&P)

http://www.ijmp.jor.br

v. 11, n. 8, Special Edition ISE, S\&P - May 2020

ISSN: 2236-269X

DOI: 10.14807/ijmp.v11i8.1203

\title{
TECHNOLOGY OF OPERATIONAL MANAGEMENT IN THE ACTIVITIES OF PORT ELEVATORS
}

\author{
Inna Kuznetsova \\ Odessa National Economic University, Ukraine \\ E-mail: innastream27@gmail.com \\ Yuliia Karpenko \\ Odessa National Economic University, Ukraine \\ E-mail: juliakarpenko50@gmail.com \\ Iryna Vidomenko \\ Odessa National Academy of Food Technology, Ukraine \\ E-mail:viaonaft@gmail.com \\ Submission: $12 / 13 / 2019$ \\ Revision: $1 / 7 / 2020$ \\ Accept: 1/15/2020
}

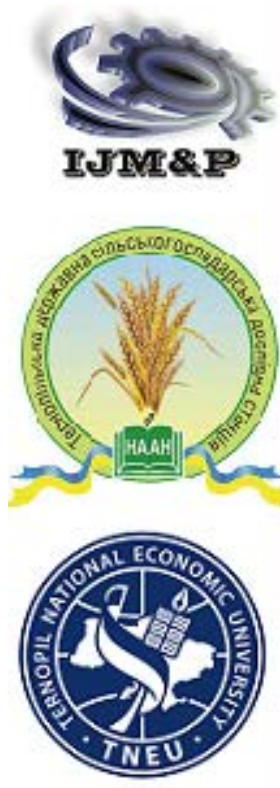

\section{ABSTRACT}

The article deals with the main problems of port elevators, which lead to incomplete use of their capacities. They include: the problem of reducing the capacity factor of the elevator capacity, the problem of lack of rhythm of grain picking operations, the problem of inconsistency with railway transport, the problem of storage of different crops and crops of different quality, the problem of loss of time during the shipment of grain to the ship. The necessity of detailed planning of port elevators' operations by the determination of flows of work passing through the system, as well as the control of their implementation, is proved. The graphical model of implementation of the operational function of the port elevator is suggested, which will allow to coordinate its operations and to check the possibility of their implementation during the departure period of the ship. This model establishes the order of operations, as well as the main planning documents that regulate them. The use of a technological map of the implementation of the operational function for describing the list and sequence of basic operations for the formation of a ship batch and its shipment, conditions and requirements for their implementation, as well as information about the equipment used, is suggested. 
DOI: 10.14807/ijmp.v11i8.1203

The graphical model and the technological map of the implementation of the port elevator's operational function provide information on the rational sequence and coherence of the operations' planning for the formation of the ship party and its shipment, which reduces the time loss, provides the opportunity to coordinate the work of the elevator with its transportation system.

Keywords: operational management technology; port elevator; operational function of the enterprise; Johnson's rule of planning of the sequence of operations

\section{INTRODUCTION}

Grain market of Ukraine is a strategically important sector of the national economy. Its successful functioning provides an opportunity to solve not only the problem of food security of the country, but also the flow of foreign currency funds to the trade balance of the country. Ukraine has today strengthened its position on the world grain market and is steadily one of the three leaders of its exports.

An important element in the export of grain is port elevators. Due to the profitability of the grain business, their quantity and capacity is constantly increasing. If in 2013 the capacity of grain terminals was estimated by grain market operators to be 35-45 million tons, then in 2017 it grew to 60.7 million tons. In many publications such capacity is estimated as sufficient due to the average amount of exported grain 40 million tons.

However, this capacity is the total value of the productivity of the loading and unloading terminal equipment. It does not take into account the possibility of receiving grain by terminals, as well as the limited transport entrances to port elevators. Therefore, grain-handling capacities continue to be built. According to UkrAgroConsult analysts by 2020, with the implementation of the announced projects the capacity of transshipment of grain will have increased by another 29.6 million tons.

Everything mentioned above suggests that the available capacity is not fully used, and the construction of additional capacities will lead to increasing competition between the terminals. This raises the urgent of forming their stable competitive advantages. Under such circumstances, achieving success in a complex competitive environment is possible through the formation and implementation of modern management technologies. And first of all, it concerns the technologies of operational management, which provide the most efficient use of the power of the enterprise. 
ISSN: $2236-269 X$

DOI: 10.14807/ijmp.v11i8.1203

\section{LITERATURE REVIEW}

The analysis of the current state and problems of the operational management of the enterprise, the study of operating systems, the improvement of the quality of operating processes are devoted to the scientific works of many foreign and domestic scientists, namely: Anand and Gray (2017), Zakharov (2017), Kapinos (2018), Kozlovskyi and Kobsev (2017), Kravtsov (2018), Mayer and Liker (2017), Chase, Akvilano and Jacobs (2019).

So, scientists (ANAND, 2017; KAPINOS, 2018; KOZLOVSKY, 2017; CHASE, 2019) comprehensively explore the theoretical foundations of operational management: its basic concepts, content and essence of operating strategy, features and typology of operating systems, management of their design and ongoing operation, etc. In addition, these scientists provide specific practical tools for modeling the operating system, the organization of the operational process in time and space, decision-making in the field of material and inventory management.

Well-known researchers of modern management technologies (MAYER; LIKER, 2017) study values, key skills, behaviors and procedures that allow managers to make decisions that combine business strategy and operational excellence, enhance their weaknesses and secure persistent success of the organization. Scientists emphasize that to ensure the successful development of the operating system, it is necessary that the skills acquired by managers are constantly honed. Without prejudice to the achievements of these scientists, it should be noted that all the scientific studies considered more closely address the issues raised in the field of production.

A thorough analysis of the current state of operational management at foreign industrial enterprises is carried out in the work of the author (ZAKHAROVA, 2017). Based on the study, the author concluded that the composition of operational management tools used by the enterprise depends on the needs of production, scope, life cycle stage, financial condition and other factors. The scientist has indicated a number of factors that hinder the transition of organizations to new concepts of production management, but has not identified the tools and technologies of operational management that will be most effective for domestic enterprises. Again, the author's scientific achievements relate to the production sphere.

In the modern scientific literature one can find the works of authors, which investigate the peculiarities of operating systems operating in the field of services, such as restaurants, medical clinics, enterprises of rail transportation services. 
DOI: 10.14807/ijmp.v11i8.1203

Thus, the requirements for the operational management of the restaurant, the content of its operational function and its industry peculiarities are studied by scientist (KRAVTSOV, 2018). It examined the structure of the restaurant's operational management system and emphasized that its key element was staff. At the same time, the question of efficiency of using staff as a resource of the system, its workload, optimization of work schedules due to the uneven demand of consumers of food services has not been investigated.

In the work of author (FERRAND, 2018) investigates the imbalance of the potential of the medical clinic, accompanied by long waiting times for patients in the care system. It is suggested that in order to prioritize clients in the queue, the combination of traditional for the medical field indicators of the importance of clients with prompt information, in particular with its waiting time. Scientist (JUNG'S, 2019) research focuses on exploring ways to use the resources of operating the operating rooms of medical clinics for routine and unplanned operations.

The author proposes a model that allows the distribution of operating rooms for scheduled patients so that first aid patients entering the operating system with a certain degree of uncertainty receive treatment services without undue delay. It is interesting from the scientific point of view that the author approached the problem of efficient use of the facilities of the operating rooms of the clinic not only in terms of priority of care of patients of the first aid, but also minimizing the cost of operating hours of operating rooms, downtime and overheads.

A model of workforce planning and their efficient distribution across medical clinics, taking into account operational and quality requirements, is proposed in the work of scientist (CIRE, 2018). It should be emphasized that the developed model allows to optimize the work schedule of the staff and is aimed at reducing the costs of the clinic.

Author (RAUT, 2018) deals with the planning of operations of the sorting station of the railway. They offer a consolidated approach to the operational planning of the station's operations in order to minimize the average length of carriages, taking into account time constraints on arrival and departure of trains, the sequence of their movement and the number and length of access routes.

As for the problems of the development of the enterprises of the elevator industry, they receive less attention. The range of issues raised in this regard can be characterized as follows: provision of grain market of Ukraine with elevator capacities and efficiency of operation of 
DOI: 10.14807/ijmp.v11i8.1203

elevator equipment (VERNIGORA, 2017), processes occurring in grain masses during storage (KIRPA, 2018), congestion of elevator capacities (GOSHOVSKY, 2018) study of changes in the structure of world grain production and trade (THOMPSON, 2019) dependence of port elevators on the possibility of transportation of grain by rail (NDEMBE, 2018).

It should be noted that today there are no studies in the scientific literature in the field of operational management of port elevators; no ways of rational use of their resources have been studied. The issues of the formation of modern operational management technologies that contribute to increasing the rhythm of service delivery and workload have not been sufficiently developed.

The purpose of the article is to analyze the use of operational management technologies on port elevators. To create an operational management technology that would take into account the specific features of the activities of port elevators and provide the most efficient use of their capacity.

\section{METHODOLOGY (DATA AND METHODOLOGY)}

The study was conducted using the systematic approach to enterprise planning (to form a model and technological map of the implementation of the operational function of the port elevator), comparative-analytical method and the observation method (to identify the main problems of the operational activity of the port elevators).

\section{RESULTS AND DISCUSSIONS}

\subsection{Result: a number of port elevators' problems resulting in incomplete usage of their capacities have been systematized.}

According to the survey of the leading experts in grain terminals, a number of problems was identified that arise during the operational activity of port elevators and influence the rational use of their capacities:

First, the problem of decreasing of the coefficient of turnover of the elevator capacity. It characterizes the use of port elevator capacities. This problem is related to the loss of time from the accumulation of a batch of grain for shipping and its irrational formation by traders.

It should be emphasized that the same lot of grain on the port elevator initially is an input material flow (at the point of acceptance), and after a while becomes an output material flow (for example, at the berth). The particularity of a port elevator is that the largest revenue from the provision of services is derived from the shipment of grain to the vessel. 
INDEPENDENT JOURNAL OF MANAGEMENT \& PRODUCTION (IJM\&P)

http://www.ijmp.jor.br

v. 11, n. 8, Special Edition ISE, S\&P - May 2020

ISSN: $2236-269 X$

DOI: 10.14807/ijmp.v11i8.1203

This transaction has the highest tariff; therefore, it is expedient to increase the amount of the output material flow to increase the profitability of the enterprise. This requires an appropriate increase of an input flow and a reduction to the time spent by the grain in the enterprise in the internal flow. It is also necessary to optimize the amount of grain reserves during storage, since long waiting for grain shipment can reduce the number of turns of the production capacity of the port elevator, and as a consequence, reduce the amount of passage.

In order to eliminate the problem of reduction in elevator speed, it is necessary to increase the efficiency of planning the receipt and dispatch of vessels, as well as planning the shipment of batches from linear elevators, orienting the dispatch of grain from the linear elevator directly to the batch of a vessel.

Secondly, the problem of the lack of regularity of grain acceptance operations, which causes the accumulation of motor and railway transport at reception points. The emergence of this problem first of all indicates the need to optimize grain shipments from linear elevators and to form a rational composition of grain crops.

So, in the case when the railway rolling stock contains cars with different crops, it is necessary to group them according to the types of crops in a sequence, avoiding mixing of cars with different kinds. This is important in order to avoid switching from one crop to another, because it requires an additional operation to clear the process line, and ultimately, a loss of time and additional costs.

This rule also concerns motor transport. In order to avoid huge queues with cars in front of terminals, it is necessary to set a deadline for acceptance of a certain culture.

Thus, the improvement of the regularity of the grain acceptance operation requires optimization of the cargo flow of the terminal through the regulation of incoming and outgoing flows. This task can be accomplished by more efficient organization of information flows between the grain trader and the port elevator based on the planned schedule. The latter should meet the needs of operational management of cargo flows of the port elevator and the principle of the rhythm of operational management.

Third, there is a problem of inconsistency in the work with railway transport. It reveals itself in two aspects. Quite often there is a delay of acceptance through demurrage of a railcar with grain, due to the lack of shunting diesel locomotives for the delivery of cargo on the elevator. Or else the problem is revealed in the absence of cargo at the dispatch station or an excess of cars on the territory of the elevator. Reducing downtime of cars with grain due to the 
DOI: 10.14807/ijmp.v11i8.1203

problems of inconsistency with the railroad requires from the company scheduling of grain deliveries by railway transport. This schedule should be formed by each grain trader, and the port elevator should work out a schedule for all grain traders.

Fourth, the problem of placing different cultures and cultures of different quality in storage. Port elevator should exclude mixing different cultures: to put the grain of different classes on the storage in the same silo, and even more so different crops is prohibited. Without clear placement planning, there may not be enough operational capacities to store and form several ship batches. In addition, there is a need to clean silos when moving from one crop to another, which, as mentioned above, involves additional expenses.

During storage of grain, the problem of losses often occurs due to mistakes in the placement of grain batches when the grain with different qualitative characteristics is mixed. This leads to deterioration in the quality of the original material flow.

For rational placement of grain batches and avoiding mistakes in this operation, it is advisable to carefully plan the import and shipment of each batch of grain, as well as its placing on storage.

Fifth, the problem of the loss of time during the shipment of grain to the vessel. Loss of time is due to a number of reasons, such as:

- lack of reliable information from grain traders about the planned amount of grain shipment. This is the most widespread cause of time losses, which greatly complicates the process of managing the cargo flows of the port elevator;

- miscoordination with ship agency, in particular: incorrect determination of the date of the vessel for shipping arrival, ignoring objective operations for its prompt service (washing of the vessel after the previous cargo, preparation for grain cargo, etc.);

- miscoordination with the captain's cargo plan;

- unequal loading of the vessel due to the features of the ship loader or the structure of the vessel. This problem is solved by using manual labor in a hold;

- delayed assembling of the documents for shipment of grain abroad (certificates, orders);

- unfavorable weather conditions: strong wind and precipitation considerably increase the load time of ships or even make it impossible. 
ISSN: 2236-269X

DOI: 10.14807/ijmp.v11i8.1203

Most of the listed above time losses can be avoided by drawing up schedules for shipment of vessels which have to be accepted by grain traders. It is also necessary to develop a loading standard, taking into account the specifics of the enterprise, and offer this standard to the captain. If the results of the survey of experts of grain terminals are reflected, most of them, as the main problem, indicate a decrease in the coefficient of turnover of the capacity of the elevator (Table 1).

Table 1: Results of the survey of grain terminal specialists on the main problems of their

\begin{tabular}{|l|c|c|}
\hline \multicolumn{2}{|c|}{ activity } \\
\multicolumn{1}{|c|}{ Problems } & \multicolumn{2}{c|}{$\begin{array}{c}\text { Number of enterprises having these } \\
\text { problems }\end{array}$} \\
\cline { 2 - 3 } & absolute & relative, in \% ofthetotal \\
\hline decrease of the elevator capacity factor & 5 & 83,33 \\
lack of rhythmicity of operations of grain acceptance & 4 & 66,67 \\
inconsistency with rail transport & 4 & 66,67 \\
storage of different crops and crops of different quality & 3 & 50,00 \\
loss of time during the shipment of grain to the ship & 4 & 66,67 \\
\hline
\end{tabular}

These problems of operational activity of grain terminals can be solved through the use of operational management technology. However, port elevators do not use it today. Most port elevators try to solve the problem of rhythmic use of resources and capacities by drawing up daily schedules of equipment operation on separate sections (Figure 1). Complex planning of all operations of the enterprise is not carried out.

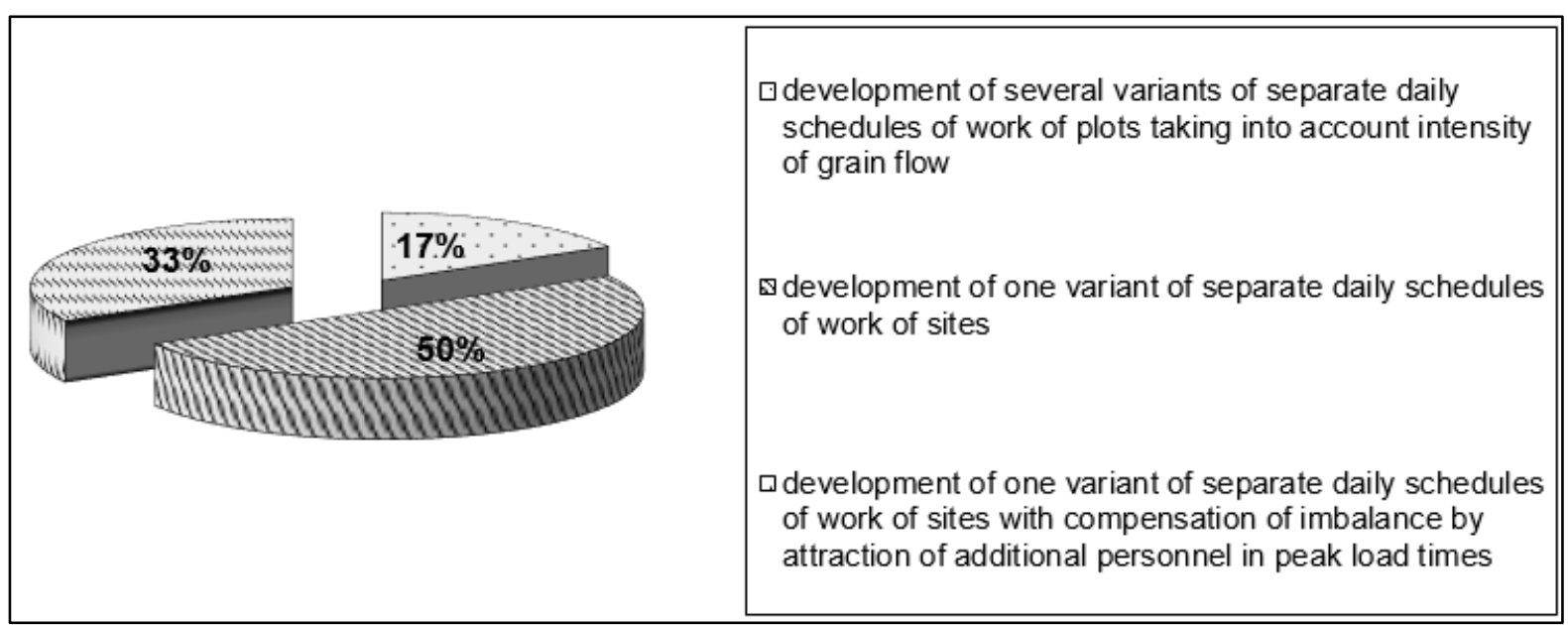

Figure 1: Ways to ensure the rhythmic use of port elevators

The formation of operational management technology, which has not been found in practical use by port elevators today, would reduce wasted time and thus make it more efficient to use their facilities. 
DOI: 10.14807/ijmp.v11i8.1203

As we have defined in previous studies, management technology is a collection of formalized knowledge of the implementation of the management process. It should contain the following information (KUZNETSOVA, 2012):

- the structure of the management process, which determines the sequence of operations;

- list of incoming and out information of each of them;

- a set of methods for receiving and transforming incoming information;

- a list of performers and resources allocated to them.

Since technology is a formalized knowledge, it is appropriate to present it through graphic models and information models of the process stages (informograms). To formulate the technology of operational management, we consider it appropriate to work out the following documents:

- graphical models of the operational management process;

- information models of planned calculations;

- informograms of the stages of the operational management process;

- technological maps of the stages of the operational management process.

Develop the following models. First of all, there is a task to develop a graphical model of the operational management process. Since the analysis of problems of port elevators proved that their implementation should take place in calendar planning, we will proceed from the definition of the sequence of the formation of such plans-graphs.

\subsection{Result: it is substantiated that for planning of port elevators activity it is expedient} to form a system of calendar planning, based on the limited loading of units, and on a combination of elements of systems of direct and backward planning of the calendar

In management theory, there are two main approaches to the formation of scheduling systems: from the point of view of loading units and from the point of view of planning in time (CHASE, 2019). The first approach distinguishes scheduling systems based on unlimited and limited unit load. In systems of the first type, the basis for the development of the unit's calendar plan is the need to perform work of a certain type. In this case, the plan is developed in a cohesive manner, its intensity is checked, but the order of work is not established. 
DOI: 10.14807/ijmp.v11i8.1203

Systems of the second type are distinguished by careful planning of all kinds of resources for all operations. In such systems, the order of the work is set (CHASE, 2019).

In accordance with the second approach, that is, from the position of the planning direction in time, the systems of direct and reverse scheduling are distinguished. Direct scheduling assumes that the company receives orders and consistently plans each future transaction. In this way, the first assessment deadline is determined. In the process of backward planning, the starting point is the date determined in the future, that is, the day on which the order must be completed. All operations are planned in reverse order. This allows you to determine the timeframe for starting an order to be completed on a certain date.

In essence, port elevators work on a special order: "forming a batch - sending a vessel. Therefore, there is a need to perform detailed planning of all operations by identifying workflows passing through the system, as well as establishing control over their fulfillment. Therefore, to plan their activities, it is advisable to form a system of calendar planning, based on the limited loading of units.

From the point of view of the direction of planning in time, port elevators are most often used by direct scheduling systems. However, such planning systems are more suitable for linear elevators, on which the grain is located for a long time, and whose profit depends on a certain extent on the duration of grain storage. For a port elevator, the work on such a schedule cannot be effective, as it reduces turnover and reduces orders from one customer through filling and over-long storage of other customers' grain.

Since the main income of the port elevator receives for the provision of services for shipments of grain to vessels, the key moment that determines the order and timing of operations of the enterprise must be the laytime of the vessel.

The term "laytime" means the period during which the charterer performs stevedoring operations in the port, not paying the owner of another board, except freight.

Indeed, the time of the start of the reference period is the greatest value, and the procedure for calculating its duration, that is, when the boat gets under load and how long it will be carried out.

In order to meet the deadlines, we suggest combining the elements of the systems of direct and reverse scheduling. As a rule, according to the principles of direct calendar planning at enterprises, the sequence and timing of all transactions with grain entering the enterprise are determined. If you apply the principles of reverse scheduling, it is appropriate to take the final 
DOI: 10.14807/ijmp.v11i8.1203

date for the formation of a ship's batch to send it to the starting point while developing a calendar plan.

The enterprise can receive information about the date of arrival of the vessel on the basis of contracts signed with the exporter. Laytime is determined on the basis of a contract between the partners or according to the standards adopted at the enterprise for the performance of cargo operations. In the first case, the number of days provided for the performance of cargo operations is set, in the second - the norms of cargo operations per unit of time are agreed.

At grain terminals, the process of shipment of grain takes place in a certain sequence, which must be taken into account when drawing up schedules. The ship's batch is first accumulated in silos, then goes through the gallery to the pier and with the help of the grainloading machine to a ship. Taking into account the structure of the ship's party, the order of loading of the vessel by grain crops is determined. As the vessel is loaded with the same grain crop, the covers of the holds are sealed and checked for leakproofness. Only then the next grain crop will be loaded.

As a rule, the company already has a certain amount of grain. Taking that into account it is determined how much more grain should be taken to form a ship's party.

\subsection{Result: using of the Johnson's rule to plan the operation of the grain processing line in the flow.}

On the elevator, the grain acceptance work consists of three stages: the determination of the quality of the grain, the establishment of its quantity and unloading. The assessment of the qualitative composition of grain entering the enterprise, as well as the determination of the need for its drying and purification, is carried out by the personnel of the production and technical laboratory with the help of modern equipment.

The sample is taken from each motor vehicle as well as each carriage of grains entering the territory of the enterprise in the order of their arrival. The organization of the work of the production and technical laboratory takes place taking into account the intensity of the incoming grain at the enterprise. On the basis of the level to which the grain isn't clean enough and damp, the amount of grain that needs to be refined is determined.

As a result of the qualitative assessment, all the grain that has passed the inspection and meets the requirements (no pests, does not exceed the degree of dampness and dirt, etc.) is transmitted for quantitative assessment, that is, for weighing. As a rule, the company has separate weights for weighing cars and railroad cars. Weighing is carried out twice. 
DOI: 10.14807/ijmp.v11i8.1203

The first time a car (a wagon) with a grain is weighed. After that, the grain is poured into a hopper and an empty machine (wagon) is weighted. Modern weight systems allow you to reduce weighing time by simultaneously weighing full and empty machines (wagons), and dividing the flow into two directions.

The corn corresponding to the basic conditions is loaded into temporary storage silos. Grain with deviations from the basic conditions is subjected to the cleaning and drying operations, or the reprocessing. It must pass through a grain dryer (if there is a deviation from the basic conditions for humidity) and/or through a separator (if there is a deviation due to dirt). The production line for grain refinement is flexible. It allows you to split and redraw the replenishment streams as needed, as different batches of cultures have different quality indicators. Accordingly, they can go through the line of refinement in different ways.

The order of the completion of crops in operations is important, as this process must be performed with minimal time loss. On port elevators, the grain processing line usually has a grain dryer, a separator, bunkers, burrows, conveyors of various types, drafts. Taking into account the productivity of all the listed above types of equipment doesn't really make a point, since according to the passport data "bottleneck" at such enterprises there are always grain dryers and separators.

That is, the performance of the product line is determined by the performance of these two types of equipment. Therefore, for the planning of works it will be appropriate to apply Johnson's rule (CHASE, 2019). Its use allows to minimize the duration of the flow - from the beginning of the first work until the time of completion of the last one.

In accordance with Johnson's rule at the stage of grain processing, it would be advisable to set the following sequence of work:

1) Make a list of operating hours for each work on the dryer and separator.

2) Choose the shortest operating time.

3) If this time corresponds with the work of the grain dryer, schedule the first performance of the drying operation. If it corresponds with the work of the separator, then schedule the final cleaning operation.

4) Repeat steps 2 and 3 for each remaining work until the calendar plan is completed.

Calculate in table 2 the processing time of grain in the stream to form a ship batch of grade 3 and 4 wheat and maize for transshipment on a Handymax vessel (the amount of 
INDEPENDENT JOURNAL OF MANAGEMENT \& PRODUCTION (IJM\&P)

http://www.ijmp.jor.br

v. 11, n. 8, Special Edition ISE, S\&P - May 2020

ISSN: 2236-269X

DOI: 10.14807/ijmp.v11i8.1203

clogging and humidity is taken into account on the basis of average enterprise data over several years).

Table 2: Calculation of the time of grain processing in the stream

\begin{tabular}{|c|c|c|c|c|c|c|c|c|c|}
\hline \multirow[t]{2}{*}{ Cereals } & \multirow[t]{2}{*}{$\begin{array}{l}\text { Amount } \\
\text { of grain, } t\end{array}$} & \multicolumn{2}{|c|}{ Quality indicators } & \multicolumn{2}{|c|}{$\begin{array}{l}\text { Deviations from the } \\
\text { basic condition }\end{array}$} & \multicolumn{2}{|c|}{$\begin{array}{c}\text { Productivity, } \mathrm{t} / \mathrm{h} \\
*\end{array}$} & \multicolumn{2}{|c|}{ Processing time, h. } \\
\hline & & 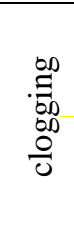 & 莺 & 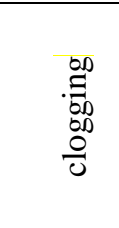 & 慧 & 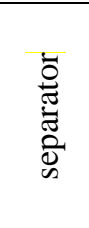 & 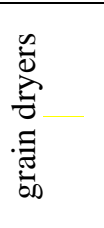 & 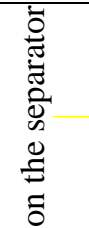 & 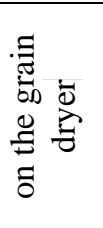 \\
\hline \multirow{4}{*}{$\begin{array}{l}\text { Wheat } \\
\text { grade } 3\end{array}$} & 30 & 2 & 15 & 1 & 1 & 200 & 250 & 0,15 & 0,12 \\
\hline & 120 & 1 & 15 & 0 & 1 & - & 250 & - & 0,48 \\
\hline & 210 & 3 & 15 & 2 & 1 & 200 & 250 & 1,05 & 0,84 \\
\hline & 490 & 2 & 14 & 1 & 0 & 200 & 250 & 2,45 & 1,96 \\
\hline \multirow{4}{*}{$\begin{array}{l}\text { Wheat } \\
\text { grade } 4\end{array}$} & 120 & 1 & 16 & 0 & 2 & - & 230 & - & 0,52 \\
\hline & 180 & 2 & 14 & 1 & 0 & 200 & - & 0,9 & - \\
\hline & 180 & 2 & 15 & 1 & 1 & 200 & 250 & 0,9 & 0,72 \\
\hline & 60 & 4 & 17 & 3 & 3 & 200 & 210 & 0,3 & 0,29 \\
\hline \multirow[t]{4}{*}{ Corn } & 150 & 2 & 16 & 1 & 2 & 180 & 230 & 0,83 & 0,65 \\
\hline & 240 & 2 & 15 & 1 & 1 & 180 & 250 & 1,33 & 0,96 \\
\hline & 180 & 4 & 16 & 3 & 2 & 180 & 230 & 1 & 0,78 \\
\hline & 150 & 2 & 15 & 1 & 1 & 180 & 250 & 0,83 & 0,6 \\
\hline
\end{tabular}

* According to the calculations, the productivity of the equipment decreases as the deviation of the grain quality indices from the basic conditions increases.

The work that has the shortest operating time is scheduled at the beginning and end of the schedule (Table 3). Thus, the parallel operation time of the equipment is maximized. This minimizes the total operating time required overall to complete the grain refining step.

Table 3: The passage of the grain line in the stream in accordance with the Johnson rule

\begin{tabular}{|c|c|c|c|}
\hline \multirow{2}{*}{ Culture } & \multirow{3}{*}{ Amount of grain, $\mathbf{t}$} & \multicolumn{2}{|c|}{ Operating time at } \\
\cline { 2 - 4 } & 120 & separators, h. & grain dryers, $\mathbf{h}$. \\
\hline \multirow{4}{*}{ Wheat grade 3 } & 490 & 0 & 0,48 \\
\cline { 2 - 4 } & 210 & 2,45 & 1,96 \\
\cline { 2 - 4 } & 30 & 1,05 & 0,84 \\
\cline { 2 - 4 } & 850 & 0,15 & 0,12 \\
\hline \multirow{5}{*}{ Wheat grade 4 } & 120 & 3,65 & 3,4 \\
\cline { 2 - 4 } & 180 & 0 & 0,52 \\
\cline { 2 - 4 } & 60 & 0,9 & 0,72 \\
\cline { 2 - 4 } & 180 & 0,30 & 0,29 \\
\cline { 2 - 4 } & 540 & 0,9 & 0 \\
\cline { 2 - 4 } & 240 & 2,1 & 1,53 \\
\cline { 2 - 4 } & 180 & 1,33 & 0,96 \\
\cline { 2 - 4 } & 150 & 1 & 0,78 \\
\cline { 2 - 4 } & 150 & 0,83 & 0,65 \\
\cline { 2 - 4 } & 3500 & 0,83 & 0,6 \\
\hline \multirow{5}{*}{ Corn } & & 15,49 & 12,85 \\
\hline
\end{tabular}


DOI: 10.14807/ijmp.v11i8.1203

Taking into account the order of loading of crops on the vessel, as well as the need for a technical break during the transition from processing of one crop to another, a schedule of grain processing in the flow is made (Table 4).

Table 4: Schedule of grain processing in the stream

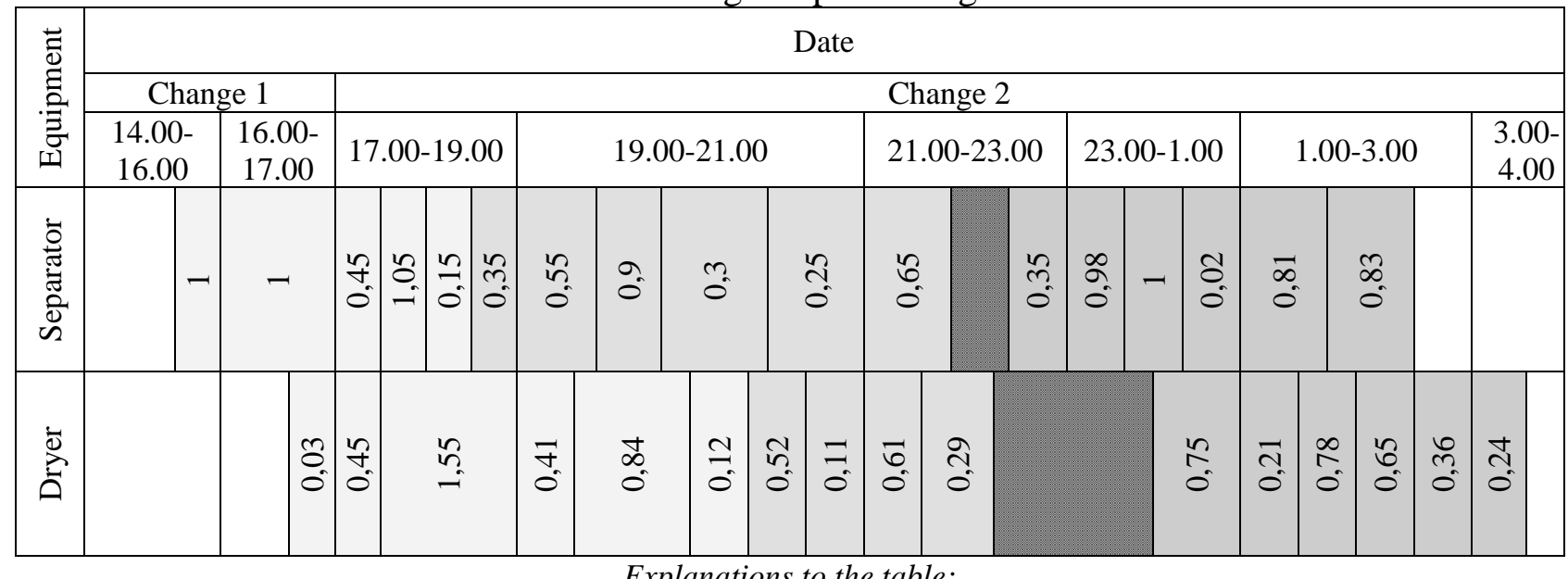

Explanations to the table:

- wheat grade 3
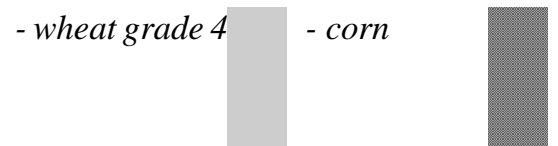

- time of reconfiguration of equipment for processing another culture

As a result of the performance of these stages of work, which have the shortest operating time, they are planned at the beginning and at the end of the schedule. Thus, the time of parallel work of equipment is maximized. This minimizes the total operating time required in general for the completion of the grain processing stage.

Consequently, the method for drawing up the schedule of grain processing suggested by us will correspond with a number of important conditions, as the following:

- will provide a minimum operating time;

- will take into account the order of loading grains on the vessel;

- will take into account the need for the transition from the completion of one grain crop to another.

Under these conditions, the shortest time for the completion of the grain processing stage will be provided.

\subsection{Result: it is proposed the graphic model of the operational function for development of the operational plan for the port elevator}

We suggest creating all shipbuilding operations in a single (aggregate) schedule of shipments of grain per ship. Its development can begin after the formation of the grain 
DOI: 10.14807/ijmp.v11i8.1203

processing schedule. The formation of a consolidated schedule for the shipment of grain to a ship requires that crops that are not needed to be processed and already accumulated in the warehouse are shipped first. In our opinion, it should be constructed as a Gantt chart, specifically: to provide information about the main operations of the process, the order and the timing of their performance.

The graph structured in such a way will provide the user with the information on the operations that are performed at each time period of shift, the time of their start and end, dependence on each other. It is structured in a form that is easy to monitor and track performed operations.

The model of this graph is presented in the table (Table 5).

The proposed model allows to check:

- the ability to perform all operations in the time of departure of the vessel;

- coordination of operations;

- performance of operations according to the established schedule.

Table 5: Model of a consolidated schedule for forming abatchof a ship and its shipment, h.

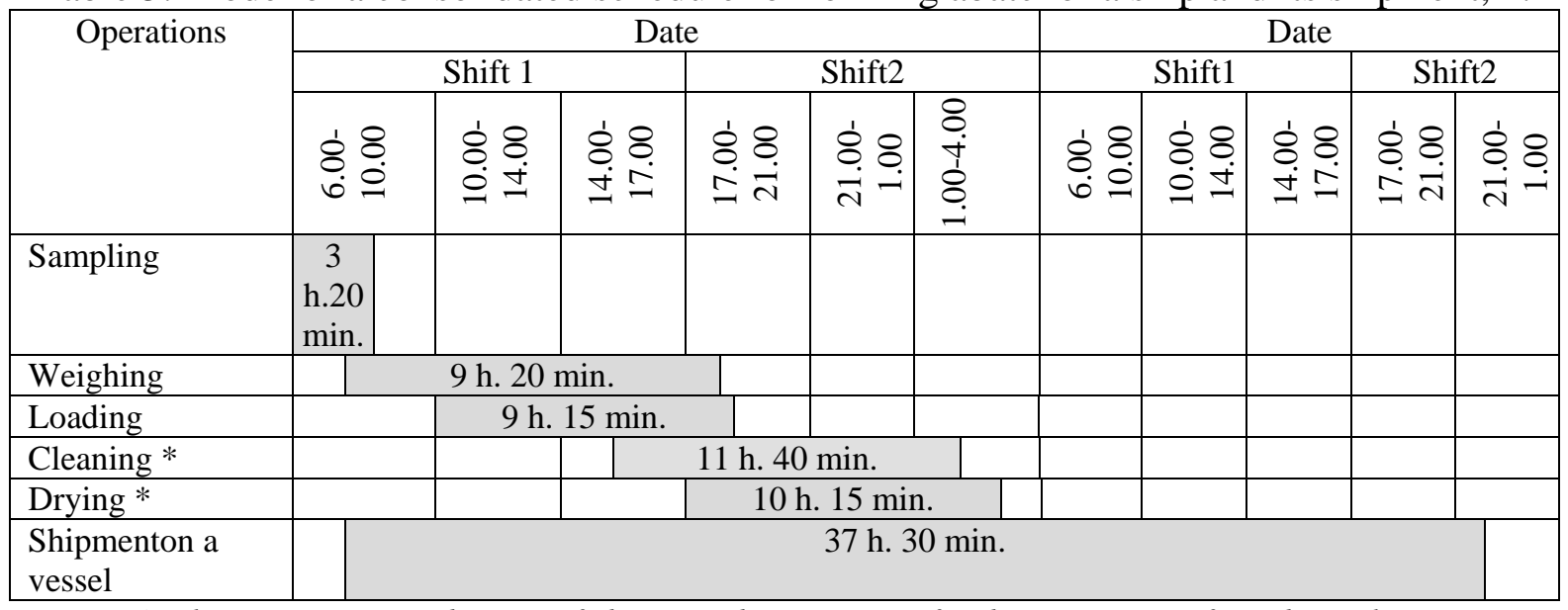

* taking into account the time of changing the equipment for the processing of another culture

We propose to perform all of the above-mentioned operations in accordance with the graphical model of the operational function of the port elevator, as the formation of a batch of a ship and its shipment (Figure 2), where the information flow shows both the sequence of information transformation and its aggregation.

The mentioned model is an important part of the formalization of the operational management of the port elevator, which establishes the order of performance of operations, as well as the main planned documents that regulate them. 
ISSN: 2236-269X

DOI: 10.14807/ijmp.v11i8.1203

In order to describe in detail, the components of the planning process for implementing the operational function of the port elevator, we consider it is necessary to use a technological map, which is also an integral part of the formalization of the technology. It should contain a list and sequence of the basic operations, conditions and requirements for their performance, information on the equipment used, information on the structural units responsible for the results of the operation, as well as the documents regulating them. The technological card is a form of visual description of the components of the process, which provides the opportunity to streamline information and verify the proper performance of operations.

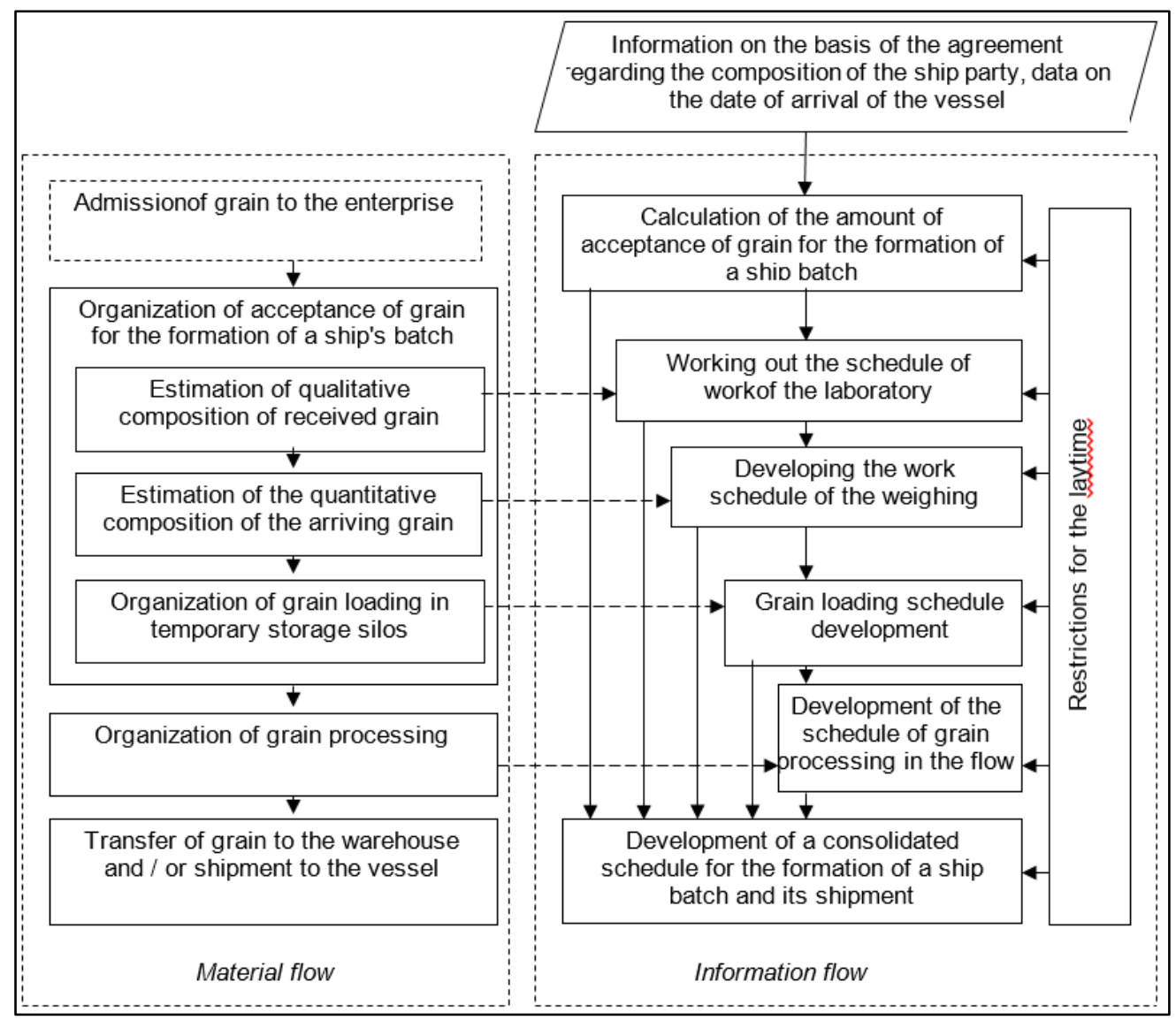

Figure 2: Model of implementation of the operational function of the port elevator

\subsection{Result: it is proposed to use the model of the technological card in accordance with the modeling methodology IDEF0}

We proposed a technological map of the process of planning the work of forming a batch of a ship and its shipment, modeled in accordance with the modeling methodology IDEF0.

It reflects the sequence of performance of basic operations of operational planning of works, the presentation of the sources of input information, as well as information on the personnel that performs the planning function (Figure 3). 
ISSN : 2236-269X

DOI: 10.14807/ijmp.v11i8.1203

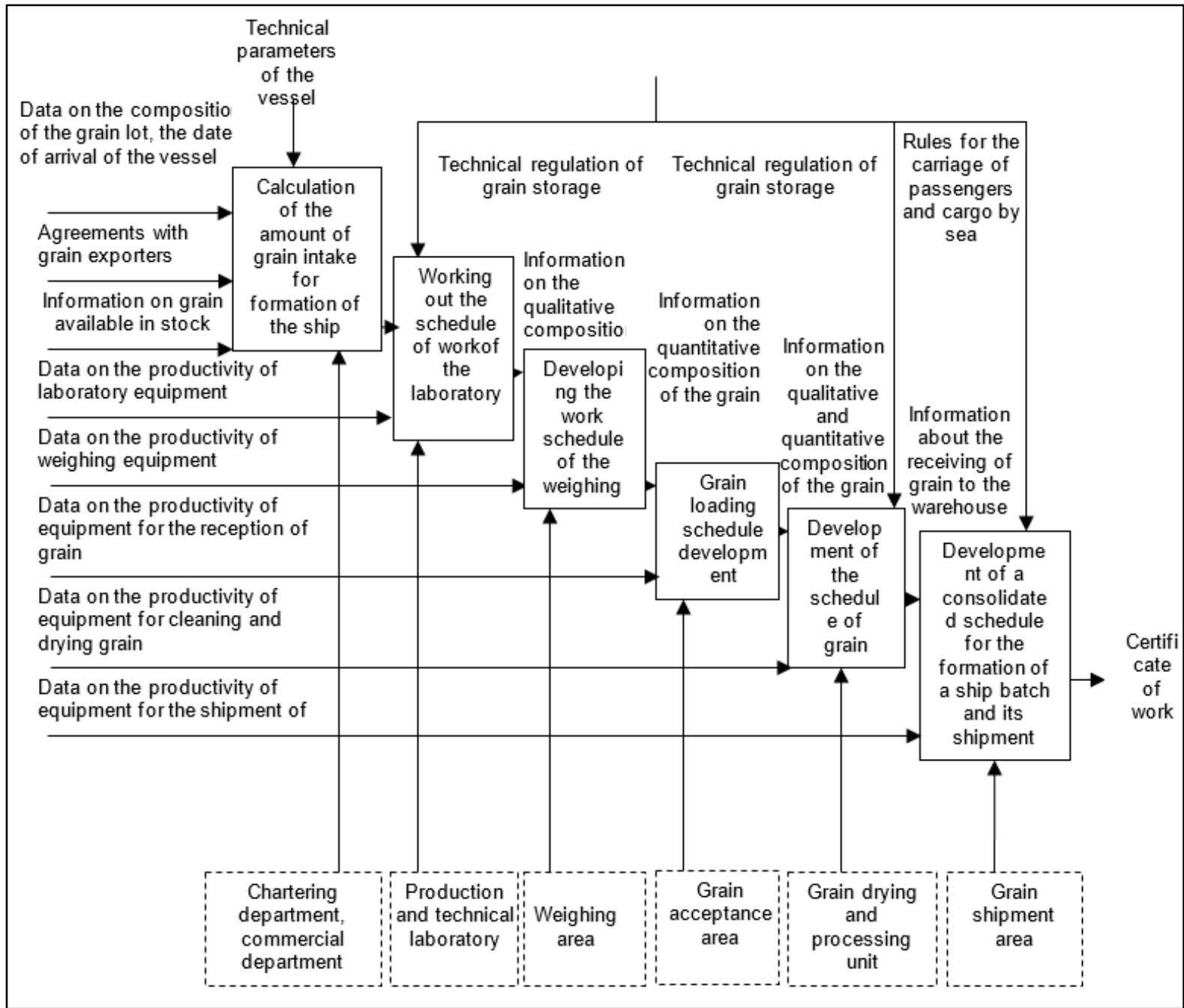

Figure 3: Technological map of implementation of the operational function of the port elevator

According to the technological card at the input of the process, there is data on the grain available in stock; available equipment and contracts for the shipment of grain, agreed with customers.

The first operation of the process is the calculation of the amount of acceptance of grain for the formation of a batch of a ship, which is carried out on the basis of providing the exporter with information on the composition of the ship batch, data on the date of arrival of the vessel and taking into account the technical parameters of the last one.

The second and third process operations involve the scheduling of the laboratory and the weighing area, respectively.

They are carried out taking into account the technical regulation of the grain composition and the productivity of the corresponding equipment. The fourth operation involves the development of a loading schedule for grain based on information about its composition, the fifth - the schedule for its completion in the flow. The last operation - the 
DOI: 10.14807/ijmp.v11i8.1203

development of a consolidated schedule for the formation of a batch and its shipment is carried out taking into account the information on the receiving of grain in the warehouse and on the basis of rules of sea transportation of passengers and cargo.

The first operation is carried out by the chartering department with the participation of the commercial department, others - by the specialists of the respective production sites. The report on the performed work on the results of all operations is transferred to the representative of the cargo owner.

Thus, we have developed important components of operational management technology, such as: a graphical model and a model of a technological map for the implementation of the operational function of the port elevator, which regulates the process of planning the work on the formation of a ship's batch and its shipment to a ship.

They provide information on the rational of consistency and interconnection in the planning of operations for the formation of a ship batch and its shipment, which reduces the loss of time, provides an opportunity to coordinate the work of the elevator with its transportation system. It provides an opportunity to increase the turnover rate of port elevators capacity and more efficiently utilize their capacity.

\section{CONCLUSIONS AND RECOMMENDATIONS}

All of the mentioned above suggests that:

1) According to the results of the survey of leading experts in port elevators, a number of problems have been systematized, resulting in incomplete usage of their capacities, such as: reduction of the coefficient of turnover of the capacity of the elevator; lack of regularity of the grain acceptance operation; inconsistency of work with the rail transport; difficulties in placing different crops and crops of different quality; loss of time during shipment of grain to a ship. It is proved that they can be solved by forming an operational management technology that reduces the loss of time and thus enables them to use their capacities more efficiently.

2) Since port elevators essentially operate in the mode of "forming a batch - sending a ship", then there is a need to perform detailed planning of all operations by identifying flows of work passing through the system, as well as establishing control over their performance. 
DOI: 10.14807/ijmp.v11i8.1203

3) It is substantiated that for planning of their activity it is expedient to form a system of calendar planning, based, first, on the limited loading of units, and secondly, on a combination of elements of systems of direct and backward planning of the calendar.

4) Development of the operational plan for the port elevator should be carried out in accordance with the graphic model of the operational function, which implies the sequence of actions: calculation of the amount of acceptance of grain for the formation of the ship batch; working out a schedule of work of the laboratory; developing the work schedule of the weighing area; development of grain loading schedule; development of the grain processing schedule in the flow; development of a consolidated schedule for the formation of a ship's batch and its shipment. The proposed model provides an opportunity to check: the possibility of performing all operations in the period of departure of the vessel; co-ordination of all operations and performance of operations in time according to the established schedule.

5) To plan the operation of the grain processing line in the flow, the Johnson's rule should be used, which allows to maximize the time of parallel work of the equipment, while minimizing the total operating time required to perform the specified work.

6) To describe the components of the operational planning process for the formation of a ship batch and its shipment, the list and sequence of basic operations, conditions and requirements for their implementation, as well as information on the equipment used, it is expedient to use the model of the technological card modeling in accordance with the modeling methodology IDEF0. It reflects the sequence of performance of the basic operations of operational planning of works, provides an idea of the sources of input information, as well as data on the personnel that performs the planning function.

7) The proposed components of operational management technology (graphic model and model of the operational map of the implementation of the operational function) provide information on the rational sequence and interoperability of operations planning, and through synchronization of work, the loss of time in the operation of the port elevator can be reduced. It provides an opportunity to increase the turn overrate of port elevators capacity and use their capacity more efficiently.

\section{REFERENCES}


ANAND, G.; GRAY, J. (2017) Strategy and organization research in operations management, Journal of Operations Management, v. 53-56, p. 1-8. DOI: https://doi.org/10.1016/j.jom.2017.09.001. Access: 15 July 2019.

CHASE, R. B.; AKVILANO, N. J.; JACOBS, R. F. (2019) Production and operational management, Moscow: Publishing house «Dialectic». p. 1094.

CIRE, A.; DIAMANT, A.; YUNES, T.; CARRASCO (2018) A Network-Based Formulation for Scheduling Clinical Rotations, Production and Operations Management, v. 28, n. 5. DOI: https://doi.org/10.1111/poms.12978. Access: 15 July 2019.

FERRAND, Y. B.; MAGAZINE, M. J.; RAO, U. S.; GLASS, T. F. (2018)

Managing responsiveness in the emergency department: Comparing dynamic priority queue with fast track, Journal of Operations Management, v. 58-59, n. 1. DOI: https://doi.org/10.1016/j.jom.2018.03.001. Access: 12 July 2019.

GOSHOVSKY, I. (2018) Why everyone builds grain terminals, Economic truth. Available at: https://www.epravda.com.ua/rus/publications/2018/11/13/642569/. Access: 12 July 2019.

JUNG, K. S.; PINEDO, M.; SRISKANDARAJAH, C.; TIWARI, V. (2019) Scheduling Elective Surgeries with Emergency Patients at Shared Operating Rooms, Production and Operations Management, v. 28, n. 6. Available at: https://doi.org/10.1111/poms.12993. Access: 15 July 2019.

KAPINOS, G. I. (2018) Product quality management in the enterprise operational management system, Bulletin of Khmelnitsky National University. Economic sciences, v. 5, n. 1, p. 147-150.

KOZLOVSKY, V. A.; KOBSEV, V. V. (2017) Production and Operations Management, St. Petersburg: Publisher of Polytechnic University. Available at: http://elib.spbstu.ru/dl/2/i16-280.pdf. Access: 10 July 2019.

KRAVTSOV, S. S. (2018) System of restaurant operational management: structure and requirements for development, Effective economy, v. 6. Available at: http://www.economy.nayka.com.ua/?op=1\&z=6416. Access: 16 July 2019.

KUZNETSOVA, I. O.; KARPENKO, Yu. V. (2012) Business Planning: A Structural Aspect, Odessa: Atlant, p.209

KYRPA, M. (2018) Self-heating and caking of grain, Grain: Journal of Modern AgroIndustrialist. Available at: https://www.zerno-ua.com/journal/2018/dekabr-2018god/samozigrivannya-ta-zlezhuvannya-zerna. Access: 17 July 2019.

LIKER, J. (2018) Leadership at all levels of lean manufacturing. Practical Guide, Moscow: Alpina Pablisher. p. 336.

MAYER, D.; LIKER, J. (2017) Practise Дao Toyota. A guide to implementing management principle. Series "Leading Corporate Management Models", Moscow: Alpina Publisher. p. 586.

NDEMBE, E.; BITZAN, J. (2018) Grain freight elevator consolidation, transportation demand, and the growth of shuttle facilities, Research in Transportation Economics, v. 71, p. 54-60. DOI: https://doi.org/10.1016/j.retrec.2018.10.001. Access: 16 July 2019.

RAUT, S.; KUMAR, S.; KHADILKAR, H.; SALSINGIKAR, S. (2019) A rolling horizon optimisation model for consolidated humpyard operational planning, Journal of Rail

Transport Planning \& Management, v. 9, p. 3-21. DOI:

https://doi.org/10.1016/j.jrtpm.2018.09.002. Access: 14 July 2019. 
THOMPSON, W.; DEWBREB, J.; PIERALLIC, S.; SCHROEDERE, K.; DOMÍNGUEZD, I. P.; WESTHOFFA, P. (2019) Long-term crop productivity response and its interaction with cereal markets and energy prices, Food Policy, v. 84, p. 1-9. DOI:

https://doi.org/10.1016/j.foodpol.2018.12.001. Access: 11 July 2019.

VERNYGORA, R. V.; RUSTAMOV R. S. H. (2017) Analysis of the Ukrainian grain storage system, Transportation systems and transportation technologies. Collection of scientific works V. Lazaryan, v. 13, p. 10-18.

ZAHAROV, V. A. (2017) Analysis of the current state of operational management at foreign industrial enterprises, Young scientist, v. 1, n. 41, p. 589-593. 